J.-W. Kim • S.-H. Nam • K.-T. Jang • S.-H. Lee •

C.-C. Kim · S.-H. Hahn • J. C.-C. Hu • J. P. Simmer

\title{
A novel splice acceptor mutation in the DSPP gene causing dentinogenesis imperfecta type II
}

Received: 18 February 2004 / Accepted: 21 April 2004 / Published online: 6 July 2004

(C) Springer-Verlag 2004

\begin{abstract}
The dentin sialophosphoprotein (DSPP) gene (4q21.3) encodes two major noncollagenous dentin matrix proteins: dentin sialoprotein (DSP) and dentin phosphoprotein (DPP). Defects in the human gene encoding DSPP cause inherited dentin defects, and these defects can be associated with bilateral progressive high-frequency sensorineural hearing loss. Clinically, five different patterns of inherited dentin defects are distinguished and are classified as dentinogenesis imperfecta (DGI) types I, II, and III, and dentin dysplasia types I and II. The genetic basis for this clinical heterogeneity is unknown. Among the 11 members recruited from the studied kindred, five were affected with autosomal dominant DGI type II. The mutation (g.1188C $\rightarrow \mathrm{G}$, IVS2-3C $\rightarrow \mathrm{G}$ ) lay in the third from the last nucleotide of intron 2 and changed its sequence from CAG to GAG. The mutation was correlated with the affection status and was absent in 104 unaffected individuals (208 alleles) with the same ethnic and geological background. The proband was in the primary dentition stage and presented with multiple pulp exposures. The occlusal surface of his dental enamel was generally abraded, and the dentin was heavily worn and uniformly shaded brown. The dental pulp chambers
\end{abstract}

J.-W. Kim · J. C.-C. Hu · J. P. Simmer $(\bowtie)$

Department of Biological and Material Sciences, University of Michigan Dental Research Laboratory,

1210 Eisenhower Place,

Ann Arbor, MI 48108, USA

e-mail: jsimmer@umich.edu

Tel.: +1-313-9759318

Fax: +1-313-9759329

J.-W. Kim $\cdot$ K.-T. Jang $\cdot$ S.-H. Lee $\cdot$ C.-C. Kim $\cdot$ S.-H. Hahn Department of Pediatric Dentistry and Dental Research Institute, College of Dentistry, Seoul National University, 28-2 Yongon-Dong, Chongno-Gu,

Seoul, 110-768, Korea

S.-H. Nam

Department of Pediatric Dentistry, College of Dentistry,

Kyungpook National University,

2-188-1 Samduk-Dong, Jung-Gu,

Daegu, 700-412, Korea appeared originally to be within normal limits without any sign of obliteration, but over time (by age 4), the pulp chambers became partially or completely obliterated. The oldest affected member (age 59) showed mild hearing loss at high-frequency $(8 \mathrm{kHz})$. Permanent dentition was severely affected in the adults, who had advanced dental attrition, premature loss of teeth, and extensive dental reconstruction.

\section{Introduction}

Dentin forms in an extracellular space, the contents of which are determined by odontoblasts, the cells that line the space and extend cellular processes into the dentin. Odontoblasts secrete type I collagen and highly specialized proteins that typically contain extensive post-translational modifications, such as glycosylations, phosphorylations, and glycosaminoglycans. These molecules are believed to control the size, shape, structure, and orientation of the mineral that forms and bring the process of mineralization under genetic control (Mann et al. 1989). Tooth formation is a complex developmental process that occurs as the result of a series of epithelial-mesenchymal interactions (Thesleff 2003; Thesleff and Jernvall 1997; Thesleff and Sharpe 1997; Tucker and Sharpe 1999). Genetic disturbances early in tooth formation can arrest tooth development. In humans, partial tooth agenesis (oligodontia) occurs in assorted patterns and is caused by defects in regulatory genes, usually encoding transcription factors (Miletich and Sharpe 2003; Vastardis 2000). Mutations in Msx1 (Vastardis et al. 1996) and Pax9 (Lammi et al. 2003; Stockton et al. 2000) result in characteristic patterns of oligodontia. When the affected regulatory gene is also involved in developmental processes other than tooth formation, the resulting familial tooth agenesis is a feature of a larger syndrome, such as ectodermal dysplasia (Bayes et al. 1998; Kere et al. 1996) or Rieger syndrome (Semina et al. 1996). Isolated malformations are believed to occur exclusively within the dental hard tissues only when genetic defects are 
manifested late in tooth formation, viz., during matrix deposition and calcification. As a consequence, candidate gene approaches to characterize the specific etiologies of dentinogenesis imperfecta (DGI) and dentin dysplasia (DD) focus on mutational analyses of the genes encoding dentin matrix proteins.

Type I collagen is the predominant protein in dentin and constitutes about $90 \%$ of the organic matrix (Linde 1989). Mutations in COL1A1 or COL1A2, encoding type I procollagen, cause more than $90 \%$ of osteogenesis imperfecta (OI), an autosomal dominant condition that primarily affects bone (Gajko-Galicka 2002). Each type of OI is subdivided based upon the presence or absence of DGI (DGI type I). The prevalence of DGI in OI patients has been reported to be $20 \%-73 \%$. The incidence of DGI is highest in OI types III and IV. In OI type I, there is a great discrepancy in the reported incidence, varying from $8 \%$ to 40\% (Malmgren and Lindskog 2003). Occasionally, reduced penetrance and the mildness of the skeletal features make DGI the predominant clinical feature that initially leads clinicians to the diagnosis of OI (Pallos et al. 2001).

The major noncollagenous proteins of dentin are dentin sialoprotein (DSP) and dentin phosphoprotein (DPP; Dimuzio and Veis 1978; Leaver et al. 1975; Linde et al. 1980; Veis and Perry 1967), which are encoded by the dentin sialophosphoprotein (DSPP) gene (Ritchie et al. 1996). Despite being translated from a single open reading frame (MacDougall et al. 1997), the DSPP chimeric protein has never been detected in dentin extracts and may be processed by proteases into DSP and DPP prior to secretion (Qin et al. 2003). DSP and DPP were originally believed to be dentin-specific proteins (Butler 1987,
1992), until DSPP mRNA was detected in the inner ear of mice by the reverse transcriptase/polymerase chain reaction method (RT-PCR) after hearing defects were discovered in DGI patients with mutations in the DSPP gene (Xiao et al. 2001). Analyses of bone protein extracts have since shown that the DSPP gene is generally expressed in bone, but at lower levels than in dentin (Butler et al. 2003; Qin et al. 2002, 2003). Whereas dentin and bone appear to contain a similar inventory of noncollagenous proteins, there are typically important differences in quantity and proteolytic processing. DSP and DPP appear to be the only extracellular constituents that are more abundant in dentin than in bone (Qin et al. 2001).

Historically, the dentin defect associated with OI has been classified as DGI type I, whereas isolated inherited dentin defects have been categorized as DGI types II and III and DD types I and II (Bixler 1976; Shields et al. 1973) that vary according to the severity of the dental phenotype. The phenotypic differences that have been used in this classification system and to make clinical diagnoses, however, do not appear to correlate with differences in their genetic etiologies. The seven DSPP mutations reported to date (Fig. 1) have been shown to cause DGI type II (Malmgren et al. 2004; Xiao et al. 2001; Zhang et al. 2001), DGI type II with deafness (Xiao et al. 2001), and DD type II (Rajpar et al. 2002). In each case, the pattern of inheritance is autosomal dominant. In addition, DSPP-null mice develop tooth defects similar to those seen in human DGI type III (Sreenath et al. 2003). Although there are other candidate genes for inherited malformations exclusive to dentin, no disease-causing mutations outside of the DSPP gene have yet been

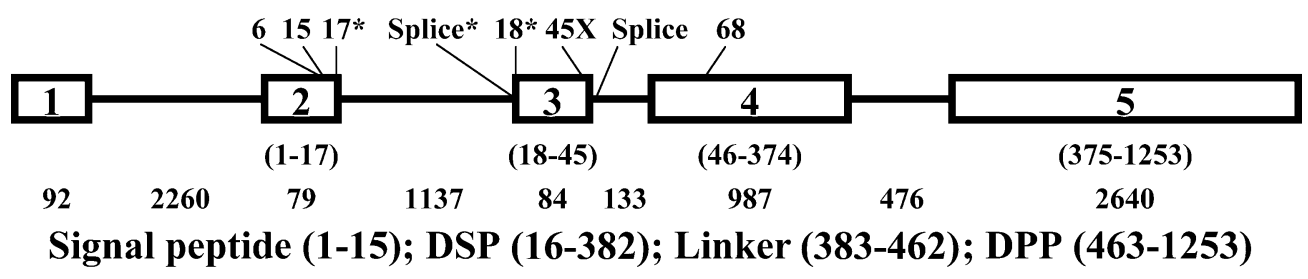

$\begin{array}{lllccc}\text { Exon 2 } & \text { p.Y6D } & \text { c.16T }>\text { G } & \text { g.16T }>\text { G } & \begin{array}{c}\text { Diagnosis } \\ \text { DD-II }\end{array} & \begin{array}{c}\text { References } \\ \text { (Rajpar et al. 2002) }\end{array} \\ \text { Exon 2 } & \text { p.A15V } & \text { c.44C }>\text { T } & \text { g.44C }>\text { T } & \text { DGI-II } & \text { (Malmgren et al. 2004) } \\ \text { Exon 2 } & \text { p.P17T } & \text { c.49C }>\text { A } & \text { g.49C }>\text { A } & \text { DGI-II } & \text { (Xiao et al. 2001) } \\ \text { Intron 2 } & & & \text { g.1188C }>\text { G } & \text { DGI-II } & \text { (this report) } \\ \text { Exon 3 } & \text { p.V18F } & \text { c.52G }>\text { T } & \text { g.1191G }>\text { T } & \text { DGI-II } & \text { (Xiao et al. 2001) } \\ \text { Exon 3 } & \text { p.Q45X } & \text { c.133C }>\text { T } & \text { g.1272C }>\text { T } & \text { DGI-II } & \text { (Zhang et al. 2001) } \\ \text { Intron 3 } & & & \text { g.1275G }>\text { A } & \text { DGI-II } & \text { (Xiao et al. 2001) } \\ \text { Exon 4 } & \text { p.R68W } & \text { c.202A }>\text { T } & \text { g.1474A }>\text { T } & \text { DGI-II } & \text { (Malmgren et al. 2004) }\end{array}$

Fig. 1 DSPP mutations associated with inherited dentin defects. The structure of the human DSPP gene is shown top. The exons are represented as blocks numbered 1-5, with the amino acid numbers (in parentheses) encoded by each exon being shown below. The introns are represented by lines. The number of nucleotides in each exon and intron is shown below. The locations of DSPP mutations are indicated above the gene structure. Asterisk Mutation associated with progressive hearing loss, $X$ nonsense mutation. The lower box summarizes the exon number, effect on the protein, location in genomic and cDNA sequences, diagnosis and appropriate reference (Malmgren et al. 2004; Xiao et al. 2001; Zhang et al. 2001; Rajpar et al. 2002) for each mutation reported for the human DSPP gene 
identified. Here, we report a novel splice junction mutation, viz., a $\mathrm{C}$ to $\mathrm{G}$ transversion, that lies in the third from the last nucleotide of intron 2 and that causes DGI type II in a Korean family.

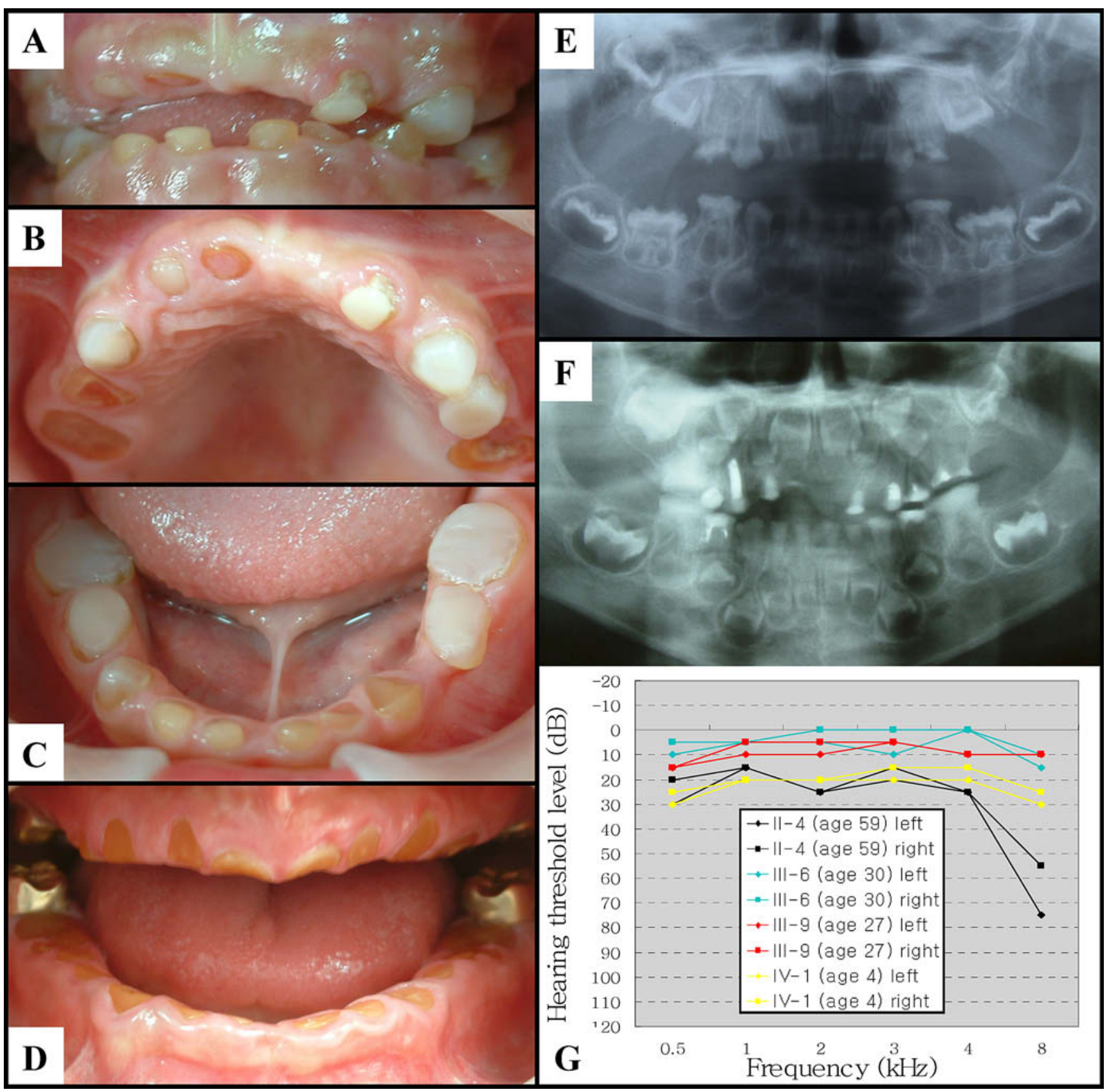

Fig. 2a-g Oral photographs and panorex radiographs from the DGI kindred. Oral photographs show the dentition of the proband (IV-1) at age $4.5(\mathbf{a}-\mathbf{c})$. All of the primary teeth show a consistent shade of brown and almost complete attrition of the enamel layer. Panorex radiographs of the proband taken at ages two (e) and 4.5 (f) are shown right. All of the maxillary teeth required endodontic therapy to treat or prevent pulp exposures and dental abscess formation secondary to rapid attrition of the protective enamel and dentin

\section{Materials and methods}

Enrollment of human subjects

The study protocol and subject consent were reviewed and approved by the Institution Review Boards at the University of Michigan and Seoul National University. Appropriate informed consent was obtained from all subjects. 
Primer design

Oligonucleotide primers for PCR were designed by using Primer3 on the web (http://www-genome.wi.mit.edu/cgi-bin/primer/primer3_www.cgi). The strategy was to generate PCR amplification products that would allow DNA sequencing of human DSPP exons 1-4 and about $50 \mathrm{bp}$ of the adjoining intron sequence on both sides of each exon. The primer pairs used for PCR amplification of genomic DNA were: exon 1 (565-bp amplification product), sense 5 -tcaccaagtgaaggaagtgg and antisense 5 '-aaagcccaaggtggattttt; exon 2 (596-bp amplification product), sense 5'-gatgtccccataaccacacc and antisense 5'-ctccatgacttctgggcatt; exon 3-4 (1,482-bp amplification product), sense $5^{\prime}$-caagccetgtaagaagccact and antisense $5^{\prime}$-acatggatgcttgtcatggt.

PCR protocol

A $10-\mathrm{cm}^{3}$ volume of peripheral whole blood was obtained from participating family members. Genomic DNA was isolated by means of the QIAamp DNA Blood Maxi Kit (Qiagen, Valencia, Calif., USA). PCR amplifications were performed by using Platinum Taq High Fidelity (Invitrogen, Carlsbad, Calif., USA). The reactions had a 5-min denaturation at $94^{\circ} \mathrm{C}$, followed by $40-50$ cycles each with denaturation at $94^{\circ} \mathrm{C}$ for $30 \mathrm{~s}$, primer annealing at $56-58^{\circ} \mathrm{C}$ for $30 \mathrm{~s}$, and product extension at $72^{\circ} \mathrm{C}$ for $30-90 \mathrm{~s}$. In the final cycle, the $72^{\circ} \mathrm{C}$ extension was for $7 \mathrm{~min}$. PCR amplification products were purified by the QIAquick PCR Purification Kit and protocol (Qiagen).

DNA sequence analysis

DNA sequencing was performed at the University of Michigan DNA Sequencing Core. The original PCR primers used to generate each amplimer were employed for the sequencing reaction. In addition, for the larger exon 3-4 amplification product, two sense primers (5'-ggaccatgggaaagaagatg and 5 '-gcatccagggacaagtaagc) and three antisense oligonucleotides (5'-cattcccttctccttgtga, 5'cctcgtttctacaggaattctca, 5'-tggaggtcttgtctccatca) were used for sequencing reactions.

Single-stranded conformational polymorphism analysis

Once the DSPP mutation was identified in intron 2, we designed PCR primers for single-stranded conformational polymorphism (SSCP) analysis (151-bp amplification product, sense 5'gtgtgcacgctcacacacat and antisense 5'-tgtactgacacatttgatcttgcta). The PCR products were mixed with formamide loading buffer (95\% formamide with bromophenol blue and xylene cyanol), heated to $95^{\circ} \mathrm{C}$ for $5 \mathrm{~min}$, quenched on ice, and loaded onto a $15 \%$ polyacrylamide gel. Electrophoresis was performed with a constant ampere mode of $15 \mathrm{~mA}$, and $250 \mathrm{~V}$ for $4 \mathrm{~h}$.

Allele-specific oligonucleotide hybridization analysis

Two oligonucleotide probes, 20 nucleotides in length and differing only at the position of the mutation identified by DNA sequencing, were synthesized (wild-type 5'-tctacttggCaggttcctca; mutant 5'tctacttggGaggttcctca). Genomic DNA samples from 104 randomly selected normal Korean subjects were amplified by using the PCR primers designed for SSCP analysis. A $20-\mu l$ aliquot of each PCR product was blotted onto a Zeta-probe nylon membrane (Bio-Rad Laboratories, Richmond, Calif., USA) and hybridized with $10 \mathrm{pmol}$ of either the wild-type or the mutant oligonucleotide probe, which was end-labeled with $\left[\gamma^{-32} \mathrm{P}\right]$ ATP $(6,000 \mathrm{Ci} / \mathrm{mmol}$; MP Biomedical, Irvine, Calif., USA) by using T4 polynucleotide kinase.

\section{Results}

The proband was a 2-year-old boy who presented with dental features consistent with a diagnosis of DGI. His oral and radiographic presentations are shown in Fig. 2. The crowns of the primary teeth were uniformly shaded brown. The dental enamel on the occlusal surfaces had worn away and exposed the underlying softer malformed dentin to rapid attrition. The dental pulp chambers appeared originally to be within normal limits without any sign of obliteration, but over time (by age 4), the pulp chambers became partially or completely obliterated. Physical examination revealed no rickets or other obvious skeletal abnormalities. The permanent dentitions of affected older individuals in this kindred were edentulous, extensively restored, or showed attrition down to the level of the gingiva, and were a uniform dark brown in color.

The family pedigree was determined and 11 members, spanning three generations, were recruited for mutational analyses (Fig. 3). DNA sequence analysis showed that the proband had a mutation (CAG to $\mathrm{GAG}$, g. $1188 \mathrm{C} \rightarrow \mathrm{G}$, IVS2-3C $\rightarrow \mathrm{G}$ ) in the third nucleotide from the end of intron 2 in one of his two DSPP alleles (the nucleotide number for this mutation was determined by counting from the first nucleotide of the translation initiation codon of the human DSPP gene sequence, accession no. AF163151). The intron 2/exon 3 junction was amplified from the 11 recruited family members, and SSCP analysis showed a unique band among the amplification products from the five affected members only (Fig. 3). Allelespecific oligonucleotide (ASO) hybridization analysis of more than 200 DSPP alleles did not detect this mutation, suggesting that this $\mathrm{C}$ to $\mathrm{G}$ transversion is not a common polymorphism in the general Korean population. Although a $\mathrm{C}$ in the -3 position of an intron splice acceptor is generally favored (78\% of GU-AG introns), a $\mathrm{G}$ is almost never observed (Padgett et al. 1986). This $C$ in the -3 position of intron 2 is conserved in the three DSPP genes that have been characterized (Fig. 3). On the basis of these findings, we concluded that the IVS2-3C $\rightarrow$ G mutation in the DSPP gene causes DGI in this kindred.

Hearing tests were conducted on four of the affected members of this kindred (Fig. 2g). Pure-tone audiometry (air-conduction thresholds and bone-conduction thresholds) and speech audiometry (speech detection thresholds and speech reception thresholds) hearing tests were used. Only the oldest member (age 59) showed mild bilateral sensorineural hearing loss, which was at the highest frequency tested $(8 \mathrm{kHz})$.

\section{Discussion}

There are now eight point mutations, all dominant in their patterns of inheritance, that have been identified in the human DSPP gene in families with inherited dentin defects. A p.Y6D mutation in the coding region for the signal peptide results in a DD-II phenotype, which is distinguishable from DGI-II by the lack of brown 


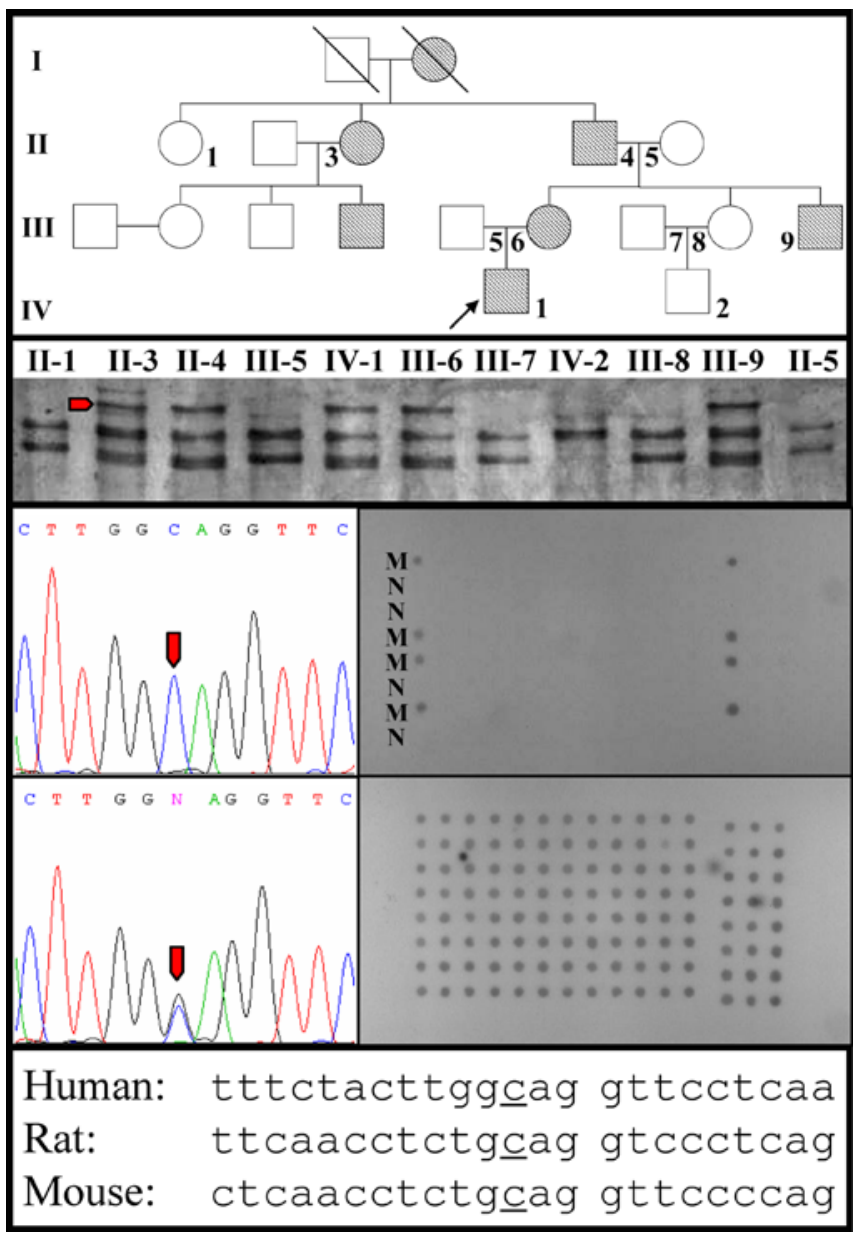

Fig. 3 Mutation analysis of the DSPP gene. Top row Pedigree of the proband's family (arrow proband). Affected members are shaded. The 11 family members willing to participate in the study are numbered. Second row SSCP analysis of intron 2/exon 3 showed that the intron 2 mutation (red arrowhead) is only found in the affected individuals (II-3, II-4, III-6, III-9, and IV-1). Third row left DNA sequencing chromatograms of the PCR amplification of intron 2/exon 3 from a wild-type individual (above) and the proband (below). A red arrowhead marks the position of the mutated nucleotide. Third row right ASO hybridization of intron 2/exon 3 PCR amplification products by using mutant (top) and wild-type (bottom) radiolabeled oligonucleotides. DNA from the four affected $(M)$ and four unaffected $(N)$ recruited members of the DGI kindred were spotted on both sides of the membrane as experimental controls. The blots of the four affected members were the only samples to show positive hybridization to the mutant oligonucleotide. Bottom row The splice acceptor site consensus sequence is shown aligned with the intron 2/exon 3 junctions of the human (AF163151), rat (AJ278306), and mouse (AJ002141) DSPP genes

discoloration in the permanent dentition (Rajpar et al. 2002). This mutation (p.Y6D) appears to impede the secretion of the DSPP protein, so that roughly half of the normal amount of protein is secreted into the dentin matrix. Point mutations in codons 17 and 18 (p.P17T and p.V18F), which are two and three amino acids away from the signal peptide cleavage site, respectively, produce the DGI-II phenotype together with progressive sensorineural high-frequency hearing loss (DFNA39/DGI1, MIM 605594; Xiao et al. 2001). These amino acid substitutions might disrupt the folding of the DSP protein directly, or indirectly by interfering with proper signal peptide cleavage. Proper DSPP expression could be critical for the correct formation of the inner ear, but other factors may also play a role in the maintenance of full hearing. Jaw position is known to affect the shape of the inner ear (Oliveira et al. 1992), and tooth loss, even in the absence of DGI, can lead to hearing deficits (Lawrence et al. 2001; Nagasaka et al. 2002). A person with DGI typically experiences significant dental attrition and premature loss of teeth, and consequently, a decrease in the occlusal vertical dimension with altered jaw position during chewing. Depending upon the degree of dental restoration, a loss of occlusal vertical dimension in patients with DGI1/DFNA39 is plausible and might have caused or contributed to their bilateral progressive hearing loss.

It will be interesting to determine whether the progressive hearing loss in patients with DSPP mutations causing DGI can be prevented by dental restoration. We need to know more about the role of DSPP in bone formation, the possible inner ear deformities in patients with DSPP mutations, and the contributions of premature tooth loss and reduced occlusal vertical dimension in patients with inherited defects in the DSPP gene before we can understand why some DSPP mutations are associated with hearing loss while others are not. In this family, the 59-year-old affected person with no noise exposure history showed mild bilateral sensorineural high-frequency hearing loss. As this condition often accompanies aging, the association (if any) of this hearing loss with the DSPP mutation cannot be determined.

We have identified a novel point mutation that lies in the RNA splicing acceptor site in intron 2 causing the DGI-II phenotype and possibly progressive high-frequency sensorineural hearing loss. Introns can be divided into different groups according to their properties (Clark and Thanaraj 2002). Intron 2 of the human DSPP gene belongs to group A3, because its donor site sequence starts with GTA (A in the +3 position). This intron has a phase of zero (occurs between codons), a length of 1,139 nucleotides, and in the wild-type, a $\underline{C} A G G T$ acceptor site sequence at positions -3 to +2 . Mutation of the $\mathrm{C}$ in the -3 position of the splicing acceptor site (to a G) causes DGI-II in our kindred. Group A3 introns have a $\mathrm{C}$ in the -3 position $64 \%$ of the time, and a purine ( $\mathrm{G}$ or $\mathrm{A}$ ) for less than $6 \%$ (Clark and Thanaraj 2002). The previously reported p. V18F mutation which also manifests itself as DGI-II with progressive hearing loss, changes the $G$ in the +1 position of the splicing acceptor sequence to a $\mathrm{T}$ (CAG $\underline{T}$ CAGTT). A G is found in the +1 acceptor position in $49 \%$ of human group A3 introns, making it plausible that the $p$. $\mathrm{V} 18 \mathrm{~F}$ mutation $(\mathrm{g} .1191 \mathrm{G} \rightarrow \mathrm{T})$ may also diminish the ability of the splicing machinery to delete intron 2 .

About $15 \%$ of human genetic diseases are caused by point mutations at or near splice junctions (Krawczak et al. 1992; Stenson et al. 2003). Two of the eight DSPP point mutations known to cause dominant dentin malformations are in introns, and three of the other six mutations are in codons adjacent to a splice junction, although only one (p. $\mathrm{V} 18 \mathrm{~F}$ ) is in a position considered important for splicing 
(Black 2003). It is not possible to biopsy human tissues expressing DSPP mRNA, so we can only speculate the effects that the IVS2-3C $\rightarrow \mathrm{G}$ mutation has on RNA splicing. Presumably, the splicing machinery cannot process the intron 2 splice acceptor site properly. Some transcripts derived from the mutant DSPP allele might retain intron 2 with its multiple upstream in-frame translation termination codons. Such transcripts might be spliced further by the nonsense-associated alternative splicing system, or, if transported out of the nucleus, could be degraded by the nonsense-mediated decay system, which detects the presence of premature stop codons in mRNA transcripts and initiates degradation (Maquat 2002; Moore 2002; Wagner and Lykke-Andersen 2002). In other transcripts, exon 3 might not be recognized and might be deleted during splicing, as has been shown to occur in other splice acceptor site mutations (Bischoff et al. 2004). The skipping of exon 3 would maintain the reading frame but would delete 28 amino acids (18-45) from the DSP protein, leaving the DPP region unaltered.

Looking back at the dental phenotypes manifested by affected individuals in the families with eight different mutations in the DSPP gene, it is evident that there are far more similarities than differences. The major distinction between DGI-I and DGI-II is that DGI-I is associated with $\mathrm{OI}$ and generally reflects a mutation in type I collagen. The major distinction between DGI-II and DD-II is that the permanent teeth in DD-II patients do not show significant discoloration, although structural changes in secondary dentition, such as partial obliteration of the pulp chambers, are evident. Dean et al. (1997) have proposed that the inherited disturbances of dentin should be classified according to their genetic etiologies. Important benefits might be realized from such a revision, but before a genebased classification system can be instituted, more information is needed about the specific genes and mutations that cause inherited dentin defects and about the dental phenotypes associated with each mutation.

Acknowledgements We thank all the family members for their cooperation, and the students of Seoul National University, School of Dentistry for donating their blood for this study. This investigation was supported in part by the Foundation of the American Academy of Pediatric Dentistry, and USPHS Research Grants DE12769 and DE11301 from the National Institute of Dental and Craniofacial Research, National Institutes of Health, Bethesda, USA.

\section{References}

Bayes M, Hartung AJ, Ezer S, Pispa J, Thesleff I, Srivastava AK, Kere J (1998) The anhidrotic ectodermal dysplasia gene (EDA) undergoes alternative splicing and encodes ectodysplasin-A with deletion mutations in collagenous repeats. Hum Mol Genet 7:1661-1669

Bischoff AM, Luijendijk MW, Huygen PL, Duijnhoven G van, De Leenheer EM, Oudesluijs GG, Van Laer L, Cremers FP, Cremers CW, Kremer H (2004) A novel mutation identified in the DFNA5 gene in a Dutch family: a clinical and genetic evaluation. Audiol Neurotol 9:34-46
Bixler D (1976) Heritable disorders affecting dentin. In: Stewart RE, Prescott GH (eds) Oral facial genetics. Mosby, St. Louis, pp 227-261

Black DL (2003) Mechanisms of alternative pre-messenger RNA splicing. Annu Rev Biochem 72:291-336

Butler WT (1987) Dentin-specific proteins. Methods Enzymol 145:290-303

Butler WT (1992) Dentin extracellular matrix and dentinogenesis. Oper Dent 5:18-23

Butler WT, Brunn JC, Qin C (2003) Dentin extracellular matrix (ECM) proteins: comparison to bone ECM and contribution to dynamics of dentinogenesis. Connect Tissue Res 44:171-178

Clark F, Thanaraj TA (2002) Categorization and characterization of transcript-confirmed constitutively and alternatively spliced introns and exons from human. Hum Mol Genet 11:451-464

Dean JA, Hartsfield JK Jr, Wright JT, Hart TC (1997) Dentin dysplasia, type II linkage to chromosome 4q. J Craniofac Genet Dev Biol 17:172-177

Dimuzio MT, Veis A (1978) Phosphophoryns-major noncollagenous proteins of rat incisor dentin. Calcif Tissue Res 25:169-178

Gajko-Galicka A (2002) Mutations in type I collagen genes resulting in osteogenesis imperfecta in humans. Acta Biochim Pol 49:433-441

Kere J, Srivastava AK, Montonen O, Zonana J, Thomas N, Ferguson B, Munoz F, Morgan D, Clarke A, Baybayan P, Chen EY, Ezer S, Saarialho-Kere U del, Chapelle A, Schlessinger D (1996) X-linked anhidrotic (hypohidrotic) ectodermal dysplasia is caused by mutation in a novel transmembrane protein. Nat Genet 13:409-416

Krawczak M, Reiss J, Cooper DN (1992) The mutational spectrum of single base-pair substitutions in mRNA splice junctions of human genes: causes and consequences. Hum Genet 90:41-54

Lammi L, Halonen K, Pirinen S, Thesleff I, Arte S, Nieminen P (2003) A missense mutation in PAX9 in a family with distinct phenotype of oligodontia. Eur J Hum Genet 11:866-871

Lawrence HP, Garcia RI, Essick GK, Hawkins R, Krall EA, Spiro A III, Vokonas PS, Kong L, King T, Koch GG (2001) A longitudinal study of the association between tooth loss and age-related hearing loss. Spec Care Dent 21:129-140

Leaver AG, Triffitt JT, Holbrook IB (1975) Newer knowledge of non-collagenous protein in dentin and cortical bone matrix. Clin Orthop 110:269-292

Linde A (1989) The extracellular matrix of dental pulp and dentin. J Dent Res 64:523-529

Linde A, Bhown M, Butler WT (1980) Noncollagenous proteins of dentin. A re-examination of proteins from rat incisor dentin utilizing techniques to avoid artifacts. J Biol Chem 255:59315942

MacDougall M, Simmons D, Luan X, Nydegger J, Feng J, Gu TT (1997) Dentin phosphoprotein and dentin sialoprotein are cleavage products expressed from a single transcript coded by a gene on human chromosome 4. Dentin phosphoprotein DNA sequence determination. J Biol Chem 272:835-842

Malmgren B, Lindskog S (2003) Assessment of dysplastic dentin in osteogenesis imperfecta and dentinogenesis imperfecta. Acta Odontol Scand 61:72-80

Malmgren B, Lindskog S, Elgadi A, Norgren S (2004) Clinical, histopathologic, and genetic investigation in two large families with dentinogenesis imperfecta type II. Hum Genet 114:491498

Mann S, Webb J, Williams RJP (1989) Biomineralization, chemical and biochemical perspectives. Weinheim, New York

Maquat LE (2002) Molecular biology. Skiing toward nonstop mRNA decay. Science 295:2221-2222

Miletich I, Sharpe PT (2003) Normal and abnormal dental development. Hum Mol Genet 12:R69-R73

Moore MJ (2002) RNA events. No end to nonsense. Science 298:370-371 
Nagasaka H, Matsukubo T, Takaesu Y, Kobayashi Y, Sato T, Ishikawa $\mathrm{T}$ (2002) Changes and equalization in hearing level induced by dental treatment and instruction in bilaterally equalized chewing: a clinical report. Bull Tokyo Dent Coll 43:243-250

Oliveira RJ, Hammer B, Stillman A, Holm J, Jons C, Margolis RH (1992) A look at ear canal changes with jaw motion. Ear Hear $13: 464-466$

Padgett RA, Grabowski PJ, Konarska MM, Seiler S, Sharp PA (1986) Splicing of messenger RNA precursors. Annu Rev Biochem 55:1119-1150

Pallos D, Hart PS, Cortelli JR, Vian S, Wright JT, Korkko J, Brunoni D, Hart TC (2001) Novel COL1A1 mutation (G599C) associated with mild osteogenesis imperfecta and dentinogenesis imperfecta. Arch Oral Biol 46:459-470

Qin C, Brunn JC, Jones J, George A, Ramachandran A, Gorski JP, Butler WT (2001) A comparative study of sialic acid-rich proteins in rat bone and dentin. Eur J Oral Sci 109:133-141

Qin C, Brunn JC, Cadena E, Ridall A, Tsujigiwa H, Nagatsuka H, Nagai N, Butler WT (2002) The expression of dentin sialophosphoprotein gene in bone. J Dent Res 81:392-394

Qin C, Brunn JC, Cadena E, Ridall A, Butler WT (2003) Dentin sialoprotein in bone and dentin sialophosphoprotein gene expressed by osteoblasts. Connect Tissue Res 44:179-183

Rajpar MH, Koch MJ, Davies RM, Mellody KT, Kielty CM, Dixon MJ (2002) Mutation of the signal peptide region of the bicistronic gene DSPP affects translocation to the endoplasmic reticulum and results in defective dentine biomineralization. Hum Mol Genet 11:2559-2565

Ritchie HH, Shigeyama Y, Somerman MJ, Butler WT (1996) Partial cDNA sequencing of mouse dentine sialoprotein and detection of its specific expression by odontoblasts. Arch Oral Biol 41:571-575

Semina EV, Reiter R, Leysens NJ, Alward WL, Small KW, Datson NA, Siegel-Bartelt J, Bierke-Nelson D, Bitoun P, Zabel BU, Carey JC, Murray JC (1996) Cloning and characterization of a novel bicoid-related homeobox transcription factor gene, RIEG, involved in Rieger syndrome. Nat Genet 14:392-399

Shields ED, Bixler D, el-Kafrawy AM (1973) A proposed classification for heritable human dentine defects with a description of a new entity. Arch Oral Biol 18:543-553
Sreenath T, Thyagarajan T, Hall B, Longenecker G, D'Souza R, Hong S, Wright JT, MacDougall M, Sauk J, Kulkarni AB (2003) Dentin sialophosphoprotein knockout mouse teeth display widened predentin zone and develop defective dentin mineralization similar to human dentinogenesis imperfecta type III. J Biol Chem 278:24874-24880

Stenson PD, Ball EV, Mort M, Phillips AD, Shiel JA, Thomas NS, Abeysinghe S, Krawczak M, Cooper DN (2003) Human gene mutation database (HGMD): 2003 update. Hum Mutat 21:577581

Stockton DW, Das P, Goldenberg M, D'Souza RN, Patel PI (2000) Mutation of PAX9 is associated with oligodontia. Nat Genet 24:18-19

Thesleff I (2003) Epithelial-mesenchymal signalling regulating tooth morphogenesis. J Cell Sci 116:1647-1648

Thesleff I, Jernvall J (1997) The enamel knot: a putative signaling center regulating tooth development. Cold Spring Harb Symp Quant Biol 62:257-267

Thesleff I, Sharpe P (1997) Signalling networks regulating dental development. Mech Dev 67:111-123

Tucker AS, Sharpe PT (1999) Molecular genetics of tooth morphogenesis and patterning: the right shape in the right place. J Dent Res 78:826-834

Vastardis H (2000) The genetics of human tooth agenesis: new discoveries for understanding dental anomalies. Am J Orthod Dentofacial Orthop 117:650-656

Vastardis H, Karimbux N, Suthua SW, Seidman JG, Seidman CE (1996) A human MSX1 homeodomain missense mutation causes selective tooth agenesis. Nat Genet 13:417-421

Veis A, Perry A (1967) The phosphoprotein of the dentin matrix. Biochemistry 6:2409-2416

Wagner E, Lykke-Andersen J (2002) mRNA surveillance: the perfect persist. J Cell Sci 115:3033-3038

Xiao S, Yu C, Chou X, Yuan W, Wang Y, Bu L, Fu G, Qian M, Yang J, Shi Y, Hu L, Han B, Wang Z, Huang W, Liu J, Chen Z, Zhao G, Kong X (2001) Dentinogenesis imperfecta 1 with or without progressive hearing loss is associated with distinct mutations in DSPP. Nat Genet 27:201-204

Zhang X, Zhao J, Li C, Gao S, Qiu C, Liu P, Wu G, Qiang B, Lo WH, Shen Y (2001) DSPP mutation in dentinogenesis imperfecta Shields type II. Nat Genet 27:151-152 